\title{
Full Load Efficiency Estimation of Refurbished Induction Machines from No-Load Testing
}

\author{
Arbi Gharakhani Siraki, Student Member, IEEE, Pragasen Pillay, Fellow, IEEE, and Pierre Angers
}

\begin{abstract}
The efficient operation of induction machines and methods to estimate their working efficiency have received increased attention in recent years due to the growing awareness of the demand side energy management programs. Various techniques have been proposed for efficiency estimation with different requirements. Numerous works have also been published in the literature about estimating the efficiency of a machine in-situ, under the loaded condition without disturbing its operation. However, very little has been done on estimation of the efficiency of the machines after the refurbishment process in the workshops, which in fact can affect numerous machines in the industry. In this paper, a method is proposed for this purpose which requires only the no-load test. The proposed method is validated by experimental results with seven different induction machines.
\end{abstract} test

Index Terms - Induction motor, efficiency estimation, no-load

\section{INTRODUCTION}

$I^{T}$ is well known that electrical machines and more specifically induction motors utilize a significant portion of the generated energy in industrialized and developing countries [1]. Their efficient operation can provide significant energy savings with benefits for both consumers and energy suppliers.

Various techniques have been proposed for efficiency estimation. The accepted routine test methods are introduced in the IEEE standard 112 [2]. Numerous other works have also been published in the literature with the aim of estimating the efficiency of the machines in-situ, under the loaded condition without disturbing their operation. However, very little has been done to find a simple and yet reliable approach to estimate the efficiency of machines after the refurbishment process in the workshops.

It is well known that a significant number of machines in the industry are repaired at least once in their life time period. Studies in literature showed that repaired and rewound motors

Manuscript received June. 20, 2012. This work was supported in part by the R\&D program of the NSERC Chair entitled Energy efficiency in electrical machines for small renewable energy production systems established in 2009 at "Concordia University"

A. Gharakhani Siraki is with the Electrical and Computer Engineering Department of Concordia University, Montreal, QC H3G 1M8, Canada (email: arbi@ieee.org).

P. Pillay is with the Electrical and Computer Engineering Department of Concordia University, Montreal, , QC H3G 1M8, Canada and also an Adjunct Professor with the University of Cape Town, Cape Town, South Africa (email: pillay@encs.concordia.ca).

P. Angers is with LTEE-Hydro-Québec, Shawinigan, QC G9N 7N5 Canada. undertake some changes in their efficiencies. Around 1\% reduction is reported in [3], while in [4] it is claimed that in average $2 \%$ efficiency loss will occur after each rewind. In [5], it is shown that in case of a less controlled rewind, efficiency reduction of $0.6 \%$ in average and up to maximum of $1 \%$ is expected. However, in case of an accurate rewind, efficiency reduction of $0.1 \%$ in average and maximum $0.7 \%$ is observed. In [6], it is claimed that in average, $0.35 \%$ increase in efficiency was obtained after precise repair and rewind of the machines. In [6], it is mentioned that the reason behind the obtained results is that the motors employed in these tests were already in use and taken from the field, while those studied in the other literature were new machines.

Being able to estimate the full load efficiency of a machine after its repair helps the machine repair facilities to assess the quality of their work. Besides it can help industrial facilities to make better decisions over replacement or repair of their existing machines in future.

Most of electrical machine refurbishment centers cannot afford to test their machines with the well accepted efficiency test of the IEEE standard 112 method B which requires the dynamometer testing. In fact, these facilities can only start up the machines with their auto-transformers and run them at the rated no-load condition. Thus, typically they do not provide any information about the efficiency of the machine following its repair.

Numerous methods are proposed in the literature for efficiency estimation of induction machines. In [7], the slip and current based methods are proposed for in service testing. As discussed in [8] these methods are not accurate and they are highly dependent on the nameplate data and the stated rated efficiency which is not valid after repair. Loss segregation based methods such as IEEE standard 112 method E/E1 [2] or its simplified version proposed by Ontario Hydro [9] are not also appropriate for workshop testing, since they require the full load test which is not practicable in workshops. The more accurate methods such as the air-gap torque method [10], [11] or even available optimization based methods [12][17] cannot be the solution due to the same requirements.

In [18] a method is proposed for efficiency determination from start up transient data. This method needs the machine to start with nominal voltage and it also needs one loaded point, the requirements that are not feasible for refurbishment centers.

Synthetic loading is another approach proposed in [19] and [20] that does not required loading of the machine. Instead it requires the machine to be supplied either though a power electronic converter or an auxiliary generator and a transformer. Thus it is not easy to apply this method in the 
ordinary motor repair centers.

The equivalent circuit based methods such as IEEE standard 112 method F/F1 [2] or the simplified equivalent circuit method (such as the Oak Ridge National Laboratory method which is known as ORMEL96 [21]) are another techniques for the efficiency estimation problem. In [22] an equivalent circuit based method is proposed which requires a no-load and a loaded operating point to estimate the parameters of the machine. Like the previous methods, the necessity of loading the machine makes it not a realistic solution for this application.

The classical form of IEEE standard 112 method F/F1 requires a low voltage, low frequency locked rotor test to estimate the rotor parameters. The requirement of the low frequency power supply and locking the rotor makes this method infeasible for workshop applications.

The ORMEL96 [21] is a nameplate based equivalent circuit method in which the locked rotor test is avoided by assuming a locked rotor current for the machine considering the NEMA code letters "D, E, ...L" from the nameplate. In detail, the parameters of a machine are found based on an iterative approach with the goal of obtaining the same rated efficiency and locked rotor current using the rated slip, total input resistance and inductance, the assumed magnitude of the locked rotor impedance and the ratio of $X_{1} / X_{2}$ [21]. Use of empirical data from the nameplate such as locked rotor current, assumed rated slip and the rated efficiency, in the parameter estimation process degrades the accuracy of this method. Moreover, the rated efficiency which in fact should be the final outcome of the method is also used in the algorithm to find the parameters of the machine. This means the rated efficiency of the machine is assumed to be equal to the nameplate value. In addition to the inaccuracy of the nameplate data, it is not likely to have exactly the nameplate values after the repair process.

Another candidate routine that can be used along with the standard no-load test method to find the parameters of the machine is the third impedance testing method proposed in IEEE standard 112 [2]. This routine does not require the low frequency locked rotor test to estimate the motor parameters. Instead as stated in the standard it requires low voltage noload or light load test data. In this method the voltage of the machine is reduced until full load slip is achieved. Then the parameters of the rotor are calculated based on the iterative approach discussed in the next section.

This method seems very promising for workshop testing application. However, some practical concerns were raised after testing this method.

1) Based on the test results, it was seen that the full load slip is not achievable by reducing the voltage in the noload condition and a light load should be coupled to the machine. This is a barrier for workshop application due to coupling issues. Therefore, it was decided to test the method with the available data from the no-load low voltage operating point which has a smaller slip.

2) In this method, it is assumed that the leakage inductance of the rotor calculated based on the data of the machine working on no-load or light load low voltage region is also valid for the rated load condition. This assumption can be true if a noticeable amount of current flows in the machine. However in the case of the no-load low voltage condition, the current is very small. So as is shown in the next sections this assumption leads to an unacceptable error.

3) This test requires the accurate slip of the machine to be measured. However, this might not be a simple task in the workshop for the machines of different sizes.

In this paper, a simple method is proposed for full load efficiency estimation from uncoupled no-load testing. This method is the modified version of the method F1 of the IEEE standard 112, which is designed to work with the uncoupled no-load testing condition.

The only available data for this method is as follows:

1) Two line voltage and current signals at no-load condition.

2) Value of the stator resistance at the ambient temperature.

3) Nameplate data of the machine.

The paper is organized as follows: the principles of the equivalent circuit method of IEEE standard 112 and more specifically details of the third impedance testing routine are reviewed in section II. In section III, this testing routine is used to find the parameters and the efficiency of two different induction machines. As is shown, the achieved results are not satisfactory due to the existence of a problem in the method which leads to an error in the estimated parameters. In section IV, a simple test is added to the proposed method in order to modify the problem in estimating parameters. In section $\mathrm{V}$, the modified method is used to calculate the parameters and the efficiency of the two small induction machines and the results are compared with the real measured efficiencies. Section VI presents the results of the tests performed in LTEE laboratory of Hydro-Quebec on five bigger induction machines in order to verify the generality of the proposed method. The conclusions are presented in Section VII.

\section{Fundamentals of the Equivalent Circuit Based EFFICIENCY ESTIMATION METHOD}

In this section, the fundamentals of the equivalent circuit based efficiency estimation method (method F1) of the IEEE standard 112 are reviewed and the details of the third impedance testing routine are discussed.

As suggested in IEEE standard 112, the efficiency of a machine can be found based on the following steps:

1) Measure the stator resistance at the ambient temperature.

2) Perform the no-load test and measure the core losses as well as the friction and windage losses.

3) Perform the impedance test and identify the rotor resistance and leakage reactance.

4) Determine the equivalent circuit parameters from the information of the previous steps. 
5) Correct the value of the stator and the rotor resistances for the specified (rated) temperature.

6) Estimate the value of stray load loss.

7) Solve the equivalent circuit iteratively and find the proper value of the slip for the desired output.

8) Estimate the efficiency.

The first two steps are the well known routine DC measurement and the no-load tests. Thus they are not discussed here. The third step which is the impedance test is the most important part of this method. The third impedance testing routine of the IEEE standard 112 is chosen, since it does not require a low frequency locked rotor test and thus it can be simply applied in the workshop applications.

In this method the voltage of the machine is reduced until the full load slip is achieved. Then the parameters of the rotor are calculated based on an iterative approach.

The details of this method and some of the important equations are explained. Besides, some typo errors have been found in the equations of the standard. Thus, the corrected versions are presented here.

In this method, the total per phase reactance of the machine is calculated from the no-load saturation test and the curve of the total per phase reactance vs. no-load voltage is drawn as shown in Fig. 1 for the case of a typical machine.

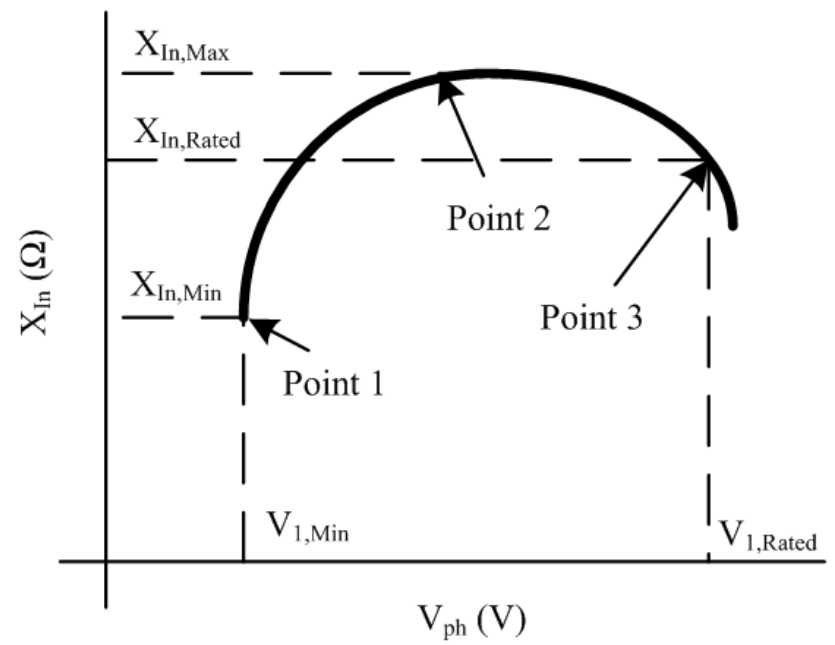

Fig. 1. Total no-load input reactance per phase vs. no-load per phase voltage In this Figure:

$\mathrm{V}_{1 \text {,Rated }}$ is the rated voltage of the machine

$\mathrm{V}_{1, \text { Min }}$ : is the minimum voltage which gives the largest possible slip

$\mathrm{X}_{\mathrm{In}, \mathrm{Rated}}$ : is the input reactance at the rated voltage

$\mathrm{X}_{\mathrm{In}, \mathrm{Min}}$ : is the input reactance at the minimum voltage

$\mathrm{X}_{\mathrm{In}, \mathrm{Max}}$ : is the maximum input reactance

To better understand the concept of the method, it is informative to see that why the no-load input reactances vs. no-load voltage curve is almost circular. The input reactance of the machine is calculated based on Fig. 2 as shown (1). In (1), $R_{C}$ is neglected for sake of simplicity.
$X_{\text {In }}=X_{1}+\left(\frac{\left(\frac{R_{2}}{s}\right)^{2}+X_{2}\left(X_{M}+X_{2}\right)}{\left(\frac{R_{2}}{s}\right)^{2}+\left(X_{M}+X_{2}\right)^{2}}\right) \cdot X_{M}=X_{1}+K \cdot X_{M}$

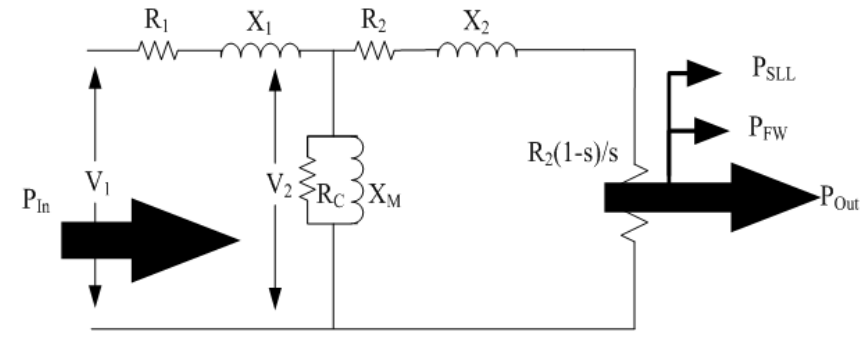

Fig. 2. Equivalent circuit of an induction machine.

Where

$\mathrm{R}_{1}$ : is the stator resistance.

$\mathrm{X}_{1}$ : is the stator leakage reactance.

$\mathrm{R}_{2}$ : is the rotor resistance.

$\mathrm{X}_{2}$ : is the rotor leakage reactance.

$\mathrm{X}_{\mathrm{M}}$ : is mutual reactance of the machine

$\mathrm{R}_{C}$ : is representative of the core losses

$\mathrm{s}$ : is the slip of the induction motor

$\mathrm{P}_{\mathrm{SLL}}$ : is the stray load loss

$\mathrm{P}_{\mathrm{FW}}$ : is the friction and windage loss

$\mathrm{P}_{\mathrm{In}}$ : is the electrical input power

$\mathrm{P}_{\text {Out }}$ : is the mechanical output power on the shaft

Three different regions can be assumed on this curve:

1) High voltage region: in this region the slip of the machine is very close to zero and therefore $\mathrm{K}$ will be very close to 1 as shown in (2).

$\operatorname{Lim}_{s \rightarrow 0} K=\operatorname{Lim}_{s \rightarrow 0}\left(\frac{\left(\frac{R_{2}}{s}\right)^{2}+X_{2}\left(X_{M}+X_{2}\right)}{\left(\frac{R_{2}}{s}\right)^{2}+\left(X_{M}+X_{2}\right)^{2}}\right) \approx \frac{\left(\frac{R_{2}}{s}\right)^{2}}{\left(\frac{R_{2}}{s}\right)^{2}}=1(2)$

Consequently, $\mathrm{X}_{\mathrm{In}}$ will be as follows:

$\mathrm{X}_{\mathrm{In}}=\mathrm{X}_{1}+\mathrm{X}_{\mathrm{M}}$

Since in this region the machine is saturated, $X_{M}$ and consequently $\mathrm{X}_{\mathrm{In}}$ decrease with increase of the voltage.

2) Medium voltage region: In this region slip is still close to zero and thus (3) is still valid. However the machine is not saturated and the value of $X_{M}$ is same as the value in the low voltage region.

3) Low voltage region: In this section of the curve, the slip of the machine starts increasing by reduction of the voltage to compensate friction and windage losses and therefore $\mathrm{K}$ is not equal to 1 anymore. Based on (4), it is possible to show that $\mathrm{K}$ is smaller than 1 and its value decreases with increase of the slip.

$\left(\mathrm{X}_{\mathrm{M}}+\mathrm{X}_{2}\right)^{2}>\mathrm{X}_{2}\left(\mathrm{X}_{\mathrm{M}}+\mathrm{X}_{2}\right) \Rightarrow \mathrm{K}<1$

So based on (1) and (4), it can be concluded that $X_{\text {In }}$ will decrease with a reduction of the voltage as shown in Fig 1. 
According to what was explained, it can be concluded that the value of the mutual reactance at point 1 and 2 are almost equal, since the machine is not yet saturated. So the data of these two points can be used to find the parameters of the machine in the low voltage region.

The following iterative approach which is proposed in IEEE standard 112 can be used to find the parameters of the machine. The initial value for the sum of the stator and rotor leakage reactances $\left(\mathrm{X}=\mathrm{X}_{1}+\mathrm{X}_{2}\right)$ is assumed to be equal to $\mathrm{X}_{\mathrm{In}, \mathrm{Min}}$.

The stator leakage reactance can be found based on (5).

$$
\mathrm{X}_{1}=\mathrm{X} \frac{\left(\frac{\mathrm{X}_{1}}{\mathrm{X}_{2}}\right)}{1+\left(\frac{\mathrm{X}_{1}}{\mathrm{X}_{2}}\right)}
$$

The ratio of $X_{1} / X_{2}$ is assumed based on the design class of the machine and the recommendation of IEEE standard 112 as shown in Table I.

TABLE I

RATIO OF $\mathrm{X}_{1} / \mathrm{X}_{2}$ BASED ON THE DESIGN ClASS OF THE MACHINE [2]

\begin{tabular}{cc}
\hline \hline Design Class & $\mathrm{X}_{1} / \mathrm{X}_{2}$ \\
\hline $\mathrm{A}, \mathrm{D}$, Wound Rotor & 1.00 \\
$\mathrm{~B}$ & 0.67 \\
$\mathrm{C}$ & 0.43 \\
\hline
\end{tabular}

Other parameters of the machine can be found based on (6) to (15). The equations (5) to (15) should be repeated until stable values of $X_{1}$ and $X_{2}$ are achieved.

$$
\begin{aligned}
& \mathrm{X}_{\mathrm{M}}=\mathrm{X}_{\mathrm{In}, \mathrm{Max}}-\mathrm{X}_{1} \\
& \theta_{1}=-\arccos \left(\frac{\mathrm{P}_{\mathrm{In}}}{3 \mathrm{~V}_{1} \mathrm{I}_{1}}\right) \\
& \mathrm{V}_{2}=\sqrt{\left[\mathrm{V}_{1}-\mathrm{I}_{1}\left(\mathrm{R}_{1} \cos \theta_{1}-\mathrm{X}_{1} \sin \theta_{1}\right)\right]^{2}+\left[\mathrm{I}_{1}\left(\mathrm{R}_{1} \sin \theta_{1}+\mathrm{X}_{1} \cos \theta_{1}\right)\right]^{2}} \\
& \theta_{2}=\arctan \frac{-\mathrm{I}_{1}\left(\mathrm{R}_{1} \sin \theta_{1}+\mathrm{X}_{1} \cos \theta_{1}\right)}{\mathrm{V}_{1}-\mathrm{I}_{1}\left(\mathrm{R}_{1} \cos \theta_{1}-\mathrm{X}_{1} \sin \theta_{1}\right)} \\
& \mathrm{I}_{\mathrm{M}}=\frac{\mathrm{V}_{2}}{\mathrm{X}_{\mathrm{M}}} \\
& \mathrm{R}_{\mathrm{C}}=\frac{\mathrm{V}_{2}{ }^{2}}{\mathrm{P}_{\mathrm{C}}} \\
& \mathrm{I}_{\mathrm{C}}=\frac{\mathrm{V}_{2}}{\mathrm{R}_{\mathrm{C}}} \\
& \mathrm{I}_{2}=\sqrt{\left[\mathrm{I}_{1} \cos \theta_{1}-\mathrm{I}_{\mathrm{M}} \sin \theta_{2}-\mathrm{I}_{\mathrm{C}} \cos \theta_{2}\right]^{2}+\left[\mathrm{I}_{1} \sin \theta_{1}+\mathrm{I}_{\mathrm{M}} \cos \theta_{2}-\mathrm{I}_{\mathrm{C}} \sin \theta_{2}\right]^{2}} \\
& \mathrm{X}_{2}=\frac{-\mathrm{V}_{1} \mathrm{I}_{1} \sin \theta_{1}-\mathrm{I}_{1}^{2} \mathrm{X}_{1}-\mathrm{I}_{\mathrm{M}}{ }^{2} \mathrm{X}_{\mathrm{M}}}{\mathrm{I}_{2}{ }^{2}} \\
& \mathrm{X}=\mathrm{X}_{1}+\mathrm{X}_{2}
\end{aligned}
$$

Then rotor resistance can be found using (16) [2] and the slip value at point 1 .
$\mathrm{R}_{2}=\mathrm{s} \sqrt{\left(\left(\frac{\mathrm{V}_{2}}{\mathrm{I}_{2}}\right)^{2}-\mathrm{X}_{2}{ }^{2}\right)}$

In [2] it is assumed that, the stable value of $X_{1}$ found from the previous equations can also be used for the rated voltage condition. Thus (17) can be employed to find the mutual inductance of the machine at the rated voltage condition.

$\mathrm{X}_{\mathrm{M}, \text { Rated }}=\mathrm{X}_{\text {In, Rated }}-\mathrm{X}_{1}$

In IEEE standard 112, it is not stated that what technique shall be used to measure the speed, however it is emphasized that the slip of the machine shall be measured accurately.

To make the method simple and applicable in workshop environment and to avoid the coupling issues, a machine current signature analysis based speed estimation technique is proposed for speed measurements in this paper.

Based on [23], the eccentricity of the rotor (due to the oval shape of the rotor) creates speed dependent current harmonics. The largest (in magnitude) speed dependent current harmonic has a frequency that can be found from (18).

$\mathrm{F}=\left(1 \pm \frac{1-\mathrm{s}}{\mathrm{P}}\right) \cdot \mathrm{F}_{\mathrm{s}}$

" $F_{\mathrm{s}}$ " is the supply frequency, " $\mathrm{s}$ " is the slip and "P" is the pole pair number. The speed dependent current harmonics are extremely small in comparison to the fundamental component of the current. Since the frequencies of these components are close to the fundamental frequency, they will be masked by the main component of the current and that makes the detection process complicated. To avoid this problem, the fundamental component of the current should be extracted from its signal. After extraction of the main component, the spectral analysis of the residual (remaining) signal can be used to detect the speed dependent current harmonics [24].

After estimating the machine parameters at the ambient temperature, the calculated values of the stator and the rotor resistances should be corrected for the specified (rated) temperature. The standard temperature rise test requires rated loading of the machine, thus it cannot be easily carried out in the refurbishments centers. If the data of rated temperature rise is available, it should be used for the correction purposes. If not, the only possible solution is to assume a value based on the insulation class of the machine and recommendations of the IEEE standard 112 as shown in Table II.

TABLE II

SPECIFIED TEMPERATURE BASED ON THE INSULATION CLASS OF THE MACHINE [2]

\begin{tabular}{cc}
\hline \hline Insulation Class & $\begin{array}{c}\mathrm{T}_{\text {Rated }} \\
\text { Temperature in }{ }^{\circ} \mathrm{C} \\
\text { (including } 25^{\circ} \mathrm{C} \text { reference ambient) }\end{array}$ \\
\hline $\mathrm{A}$ & 75 \\
$\mathrm{~B}$ & 95 \\
$\mathrm{~F}$ & 115 \\
$\mathrm{H}$ & 130 \\
\hline
\end{tabular}

The following equation can be used to correct the value of the each resistance [2]. 
$R_{\text {rated }}=\frac{R_{\text {amb }}\left(T_{\text {rated }}+K_{R}\right)}{\left(T_{a m b}+K_{R}\right)}$

In which

$R_{a m b}$ : is the value of resistance at the ambient temperature.

$\mathrm{R}_{\text {rated }}$; is the value of the resistance at rated temperature.

$\mathrm{T}_{\mathrm{amb}}$ : is the ambient temperature.

$\mathrm{T}_{\text {rated }}$ : is the rated temperature known based on available data or Table II.

$\mathrm{K}_{\mathrm{R}}$ : is 234.5 for stator resistance and 225 for rotor resistance.

The indirect measurement of the stray load loss requires the dynamometer test and the direct measurement involves the reverse rotational test. Both of these requirements are not simply achievable in a workshop environment. Therefore, same as method F1, an empirical value is assumed for the stray load loss. In this work this value is assumed based on the IEC 60034-2-1 [25] standard as shown in (20) for the machines with the output power bigger than $1 \mathrm{~kW}$ and smaller than $10 \mathrm{MW}$. The value from the IEC standard has been chosen over the one from IEEE standard 112 due to its better accuracy.

$\mathrm{P}_{\mathrm{SLL}}=\mathrm{P}_{\text {In }} \times\left[0.025-0.005 \log _{10}\left(\mathrm{P}_{\text {Out }}\right)\right]$

After estimation of all parameters, the slip of the machine at each loading condition is found iteratively. This means the slip of the machine at any load and voltage condition is found by changing the slip and solving the equivalent circuit until the desired output power is obtained.

The proper value of the slip is used in the calculation of the input power, input current and the power factor. The efficiency can be calculated based on these slips.

The above mentioned equivalent circuit based efficiency estimation algorithm is coded in the Matlab/Simulink software package and it is used to find the efficiency of a $3 \mathrm{hp}$ and 7.5 hp induction machine. The results are discussed in the next section.

\section{EXPERIMENTAL RESULTS OF THE IEEE METHOD}

In this section the above mentioned testing routine is used to estimate the efficiency of a $3 \mathrm{hp}$ and a $7.5 \mathrm{hp}$ induction machines in the laboratory. The nameplate data of these machines are shown in Tables III and IV respectively.

TABLE III

NAMEPLATE DATA OF 3 HP INDUCTION MACHINE

\begin{tabular}{cccc}
\hline \hline $\mathrm{f}$ & $60 \mathrm{~Hz}$ & Design class & $\mathrm{B}$ \\
$\mathrm{V}_{\mathrm{LL}}$ & 208 & Insulation class & $\mathrm{B}$ \\
$\mathrm{I}$ & 10.3 & Nominal speed & 1740 \\
Connection & $\mathrm{Y}$ & Poles & 4 \\
\hline
\end{tabular}

TABLE IV

NAMEPLATE DATA OF 7.5 HP INDUCTION MACHINE

\begin{tabular}{cccc}
\multicolumn{4}{c}{ NAMEPLATE DATA OF 7.5 HP INDUCTION MACHINE } \\
\hline \hline $\mathrm{f}$ & $60 \mathrm{~Hz}$ & Design class & $\mathrm{C}$ \\
$\mathrm{V}_{\mathrm{LL}}$ & $230 / 460$ & Insulation class & $\mathrm{F}$ \\
$\mathrm{I}$ & $17.7 / 8.85$ & Nominal speed & 1755 \\
Connection & $\Delta$ & Poles & 4 \\
\hline
\end{tabular}

The results of each step are shown below:

Step 1: DC measurement test to find the stator resistance.

- $3 \mathrm{hp}$ machine: $0.67 \Omega /$ phase

- $\quad 7.5 \mathrm{hp}$ machine: $0.71 \Omega /$ phase

Step 2: No-load test to find the core loss, friction and windage losses.

The input power minus the stator copper losses vs. voltage square curve is shown for the tested $3 \mathrm{hp}$ and $7.5 \mathrm{hp}$ induction machines in Fig. 3 and 4 respectively. The core losses at rated voltage condition and the friction and windage losses are shown in the following figures.

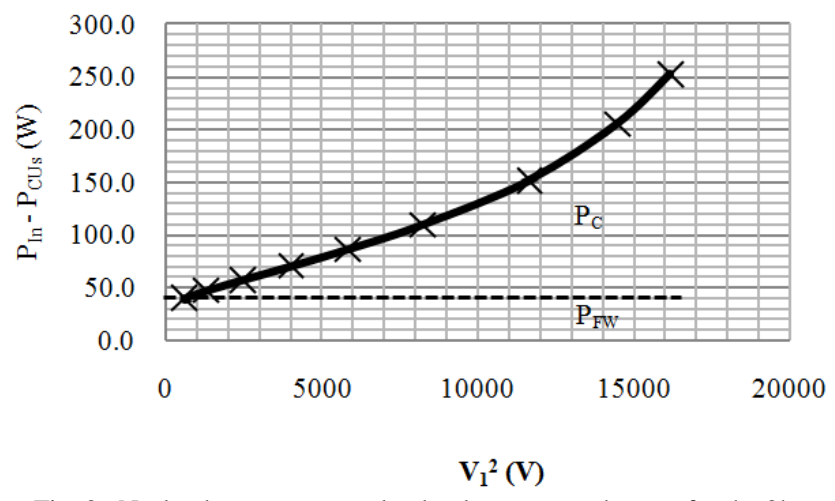

Fig. 3. No-load powers vs. no-load voltage squared curve for the $3 \mathrm{hp}$ machine

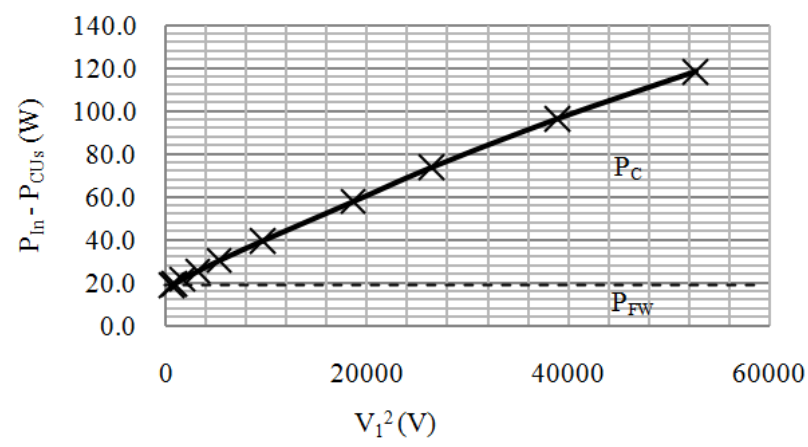

Fig. 4. No-load powers vs. no-load voltage squared curve for the $7.5 \mathrm{hp}$ machine

Step 3: The impedance test has been performed for the tested two machines. The curves of the total no-load per phase input reactance vs. no-load per phase voltages are obtained and shown in Fig. 5 and Fig. 6 respectively. 


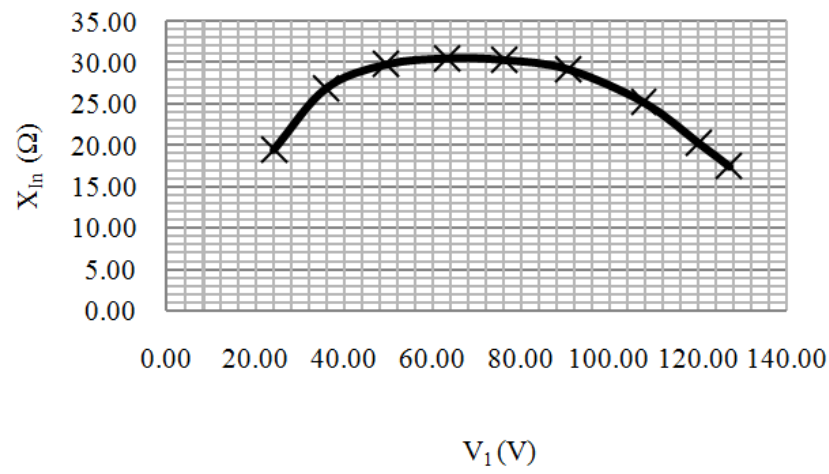

Fig. 5. No-load input reactance vs. voltage curve for the $3 \mathrm{hp}$ machine

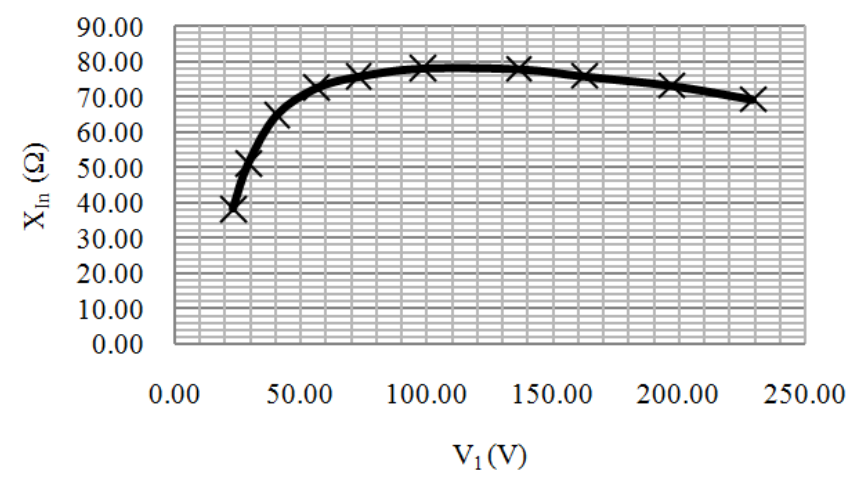

Fig. 6. No-load input reactance vs. voltage curve for the $7.5 \mathrm{hp}$ machine

As it can be seen from Fig. 5 and 6, the curves of these two machines are different in the high voltage region. This is due to the fact that the first one is a standard machine with noticeable saturation rate in the high voltage region while the second one is an energy efficient machine with very low saturation rate in the high voltage region.

The slip of the machine at the minimum voltage are extracted from the current signal as shown in Figs. 7 and 8 for the $3 \mathrm{hp}$ and $7.5 \mathrm{hp}$ machines respectively.

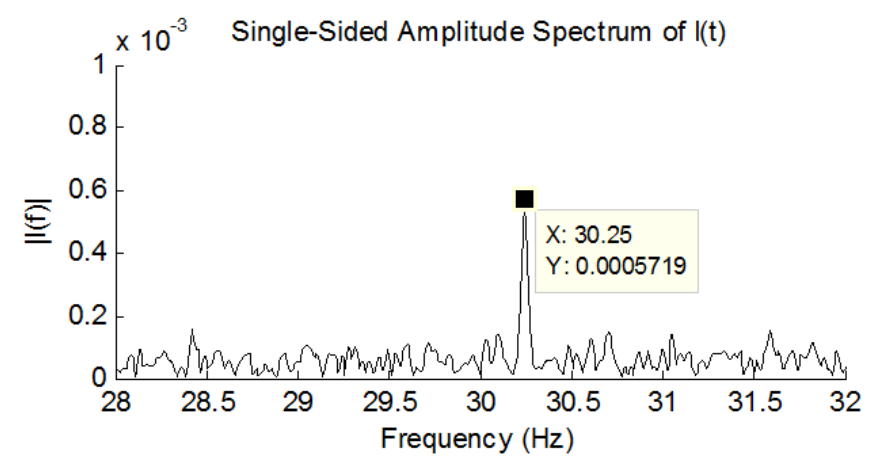

Fig. 7. Speed dependant current harmonic of $3 \mathrm{hp}$ machine at low voltage $(24 \mathrm{~V})$

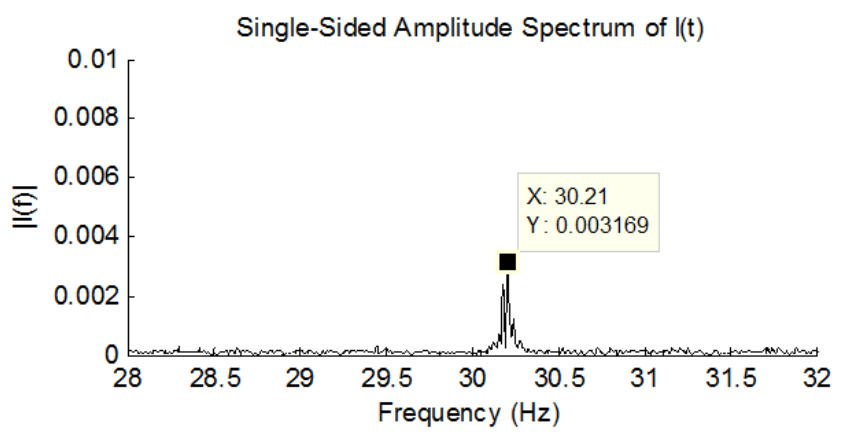

Fig. 8. Speed dependant current harmonic of $7.5 \mathrm{hp} \mathrm{machine}$ at low voltage $(23 \mathrm{~V})$

Considering (18), the number of pole pairs (equal to 2), the supply frequency $(60 \mathrm{~Hz})$ and the possible slip range from 0 to $0.055(1700 \mathrm{rpm})$, it is anticipated to have the speed dependent current harmonic somewhere between $30 \mathrm{~Hz}$ and $31.67 \mathrm{~Hz}$. As shown in Fig. 7 and Fig. 8, the frequency of this harmonic is found to be equal to $30.25 \mathrm{~Hz}$ in case of $3 \mathrm{hp}$ machine and $30.21 \mathrm{~Hz}$ in case of $7.5 \mathrm{hp}$ machine. Using (18), the frequency of $30.25 \mathrm{~Hz}$ is found equivalent to $1785.8 \mathrm{rpm}$ and $30.21 \mathrm{~Hz}$ to $1787.5 \mathrm{rpm}$. The estimation is based on 60 seconds of data acquisition with $5 \mathrm{kHz}$ sampling rate.

Step 4: The discussed iterative method of IEEE standard 112 has been coded in the Matlab/simulink software package and it is used with the obtained data from the previous steps to find the parameters of the machines. The estimated parameters are shown in Table V.

TABLE V

ESTIMATED PARAMETERS OF THE 3 HP AND 7.5 HP MACHINES

\begin{tabular}{ccc}
\hline \hline Parameters & $3 \mathrm{hp}$ & $7.5 \mathrm{hp}$ \\
\hline $\mathrm{R}_{1}$ & $0.67 \Omega$ & $0.71 \Omega$ \\
$\mathrm{X}_{1}$ & $2.37 \Omega$ & $8.77 \Omega$ \\
$\mathrm{X}_{2}$ & $3.54 \Omega$ & $20.41 \Omega$ \\
$\mathrm{R}_{2}$ & $0.32 \Omega$ & $0.38 \Omega$ \\
$\mathrm{X}_{\mathrm{M}}$ & $17.94 \Omega$ & $60.56 \Omega$ \\
$\mathrm{R}_{\mathrm{C}}$ & $198.7 \Omega$ & $1214 \Omega$ \\
\hline
\end{tabular}

Step 5: The value of the stator and rotor resistances are corrected to the specified temperature. The specified temperature of each machine has been assumed based on the insulation class of the machine and Table II. The results are shown in Table VI.

TABLE VI

CORRECTED RESISTANCES OF THE 3 HP AND 7.5 HP MACHINES

\begin{tabular}{ccc}
\hline \hline Parameters & $3 \mathrm{hp}$ & $7.5 \mathrm{hp}$ \\
\hline $\mathrm{R}_{1}$ & $0.85 \Omega$ & $0.96 \Omega$ \\
$\mathrm{R}_{2}$ & $0.41 \Omega$ & $0.52 \Omega$ \\
\hline
\end{tabular}

Step 6: The stray load losses were assumed based on (20).

Step 7: Based on the estimated parameters, the equivalent circuit has been solved iteratively to find the slip in which the machine gives the rated output power. Surprisingly, no slip 
was found with these parameters. This means the value of the estimated parameters are not correct.

To better understand the problem, the equivalent circuit of the machine has been solved using the rated speed from the nameplate. The output powers and the input currents were found as follows:

- 3 hp machine: $\mathrm{I}_{1}=10.86 \mathrm{~A}, \mathrm{P}_{\text {Out }}=2.56 \mathrm{hp}$

- 7.5 hp machine: $\mathrm{I}_{1}=7.82 \mathrm{~A}, \mathrm{P}_{\text {Out }}=2.65 \mathrm{hp}$

By comparing the results with the nameplate values, it was concluded that the input impedance of the machines were estimated much larger than their real values.

More investigation into the parameters and the source of the error makes it clear that the problem is the value of the stator and rotor leakage reactances. Consequently, the inaccurate value of the stator leakage reactance in (17) leads to an erroneous value of the mutual reactance at rated voltage condition.

In fact, the problem is in the assumption of the IEEE standard 112 which considers that the stator and rotor leakage reactances found from the proposed impedance test method in the low voltage region can also be used for the rated condition. As is shown in Fig. 9 and 10 for the tested 3hp and 7.5hp induction machines respectively, the value of current in the low voltage region is very small.

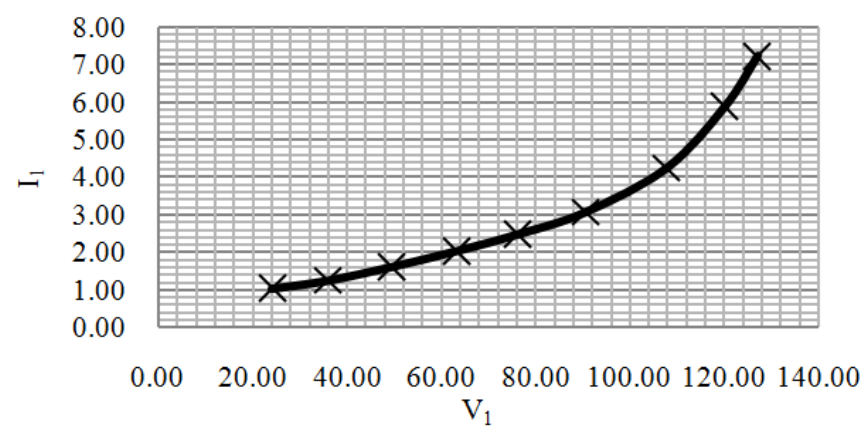

Fig. 9. No-load current vs. no-load voltage curve of the $3 \mathrm{hp} \mathrm{machine}$

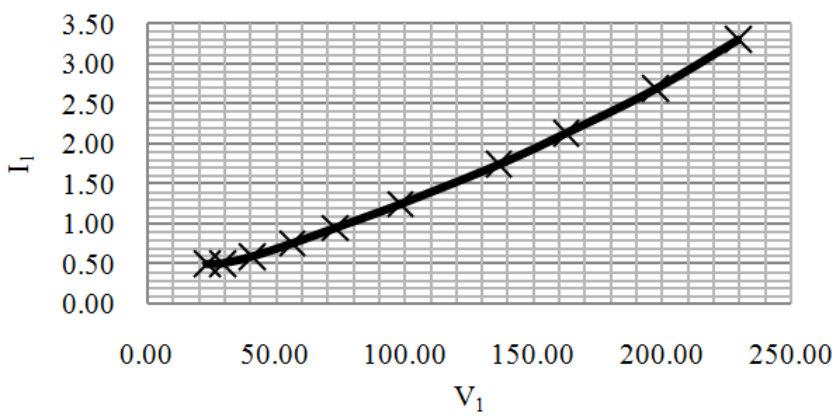

Fig. 10. No-load current vs. no-load voltage curve of the $7.5 \mathrm{hp}$ machine

Due to the very small value of the current and consequently the non saturated teeth of the machine, the reluctance of the leakage flux path in the machine is much smaller than at the rated condition. Consequently, the reactance is much larger than the rated condition where the current is higher. That is why the value obtained for leakage reactances at the low voltage region is not valid for the rated voltage condition and another method should be used to estimate these parameters at the rated condition. It should be mentioned that the value of the rotor resistance obtained in this method is still valid for the rated condition, since the rotor resistance is not dependent on the current.

\section{Proposed Modification to the IEEE Method}

In this section a simple test is proposed in order to find the values of the leakage reactances that can later be used to find the mutual reactance of the machine at the rated voltage level and finally the efficiency at any loading condition.

This test is called the "virtual locked rotor test" by the authors of the paper. As is known, in the first few cycles and before the machine starts to rotate, the situation is very similar to the locked rotor test. Consequently it should be possible to use the data of these cycles to find the leakage reactances. However, two main points should be considered.

1- In case of the rated voltage start up, the machine accelerates very fast and there is a significant electrical transient in the current. Therefore it is almost impossible to extract the locked rotor parameters. However in case of a low voltage start up, the electrical transient is smaller, the current is adequate and in addition, it takes a significant number of cycles before the machine starts up. Even after start up, the machine accelerates very slowly, so there is sufficient number of electrical cycles to extract the locked rotor parameters.

2 - Since in this condition the frequency of the rotor current is $60 \mathrm{~Hz}$, the rotor resistance calculated here cannot be used in the efficiency estimation process. However, the leakage reactance of the rotor is less dependent on the frequency than the level of the current as discussed before and thus it is good enough for the efficiency estimation process. Moreover, the value of the rotor resistance is more critical for efficiency estimation process in comparison to the rotor leakage reactance, since $R_{2} / s$ is always much bigger than $X_{2}$ in normal operation range of the motor.

The data of the voltage, current and input power is required to find the leakage reactance of the machine from the virtual locked rotor test. In this case two line voltage and current signals are used to obtain the required data. Knowing these values, the sum of stator and rotor leakage reactances can be found based on (21).

$\mathrm{X}_{1}+\mathrm{X}_{2}=\frac{\mathrm{V}_{\mathrm{vl}}}{\mathrm{I}_{\mathrm{vl}}} \times \sqrt{1-\left(\frac{\mathrm{P}_{\mathrm{vl}}}{3 \mathrm{~V}_{\mathrm{vl}} \mathrm{I}_{\mathrm{vl}}}\right)^{2}}$

In which

$\mathrm{V}_{v l}$ : Phase voltage at low voltage virtual locked rotor test

$\mathrm{I}_{v l}$ : Input current at low voltage virtual locked rotor test

$\mathrm{P}_{v l}$ : Input power at low voltage virtual locked rotor test

After this step, (5) can be used to separate rotor and stator leakage reactances and (17) can be employed to find the value of the mutual reactance at the rated voltage condition.

The proposed test has been performed with the 3hp and 7.5 hp induction machines and the results are shown in Fig.11 and 
Fig. 12. As it can be seen the rms value of the current and voltage signals are almost constant during the 60 cycles after the low voltage start up. The sum of leakage reactances has been calculated using (21) and it is shown in Fig. 13 and 14.

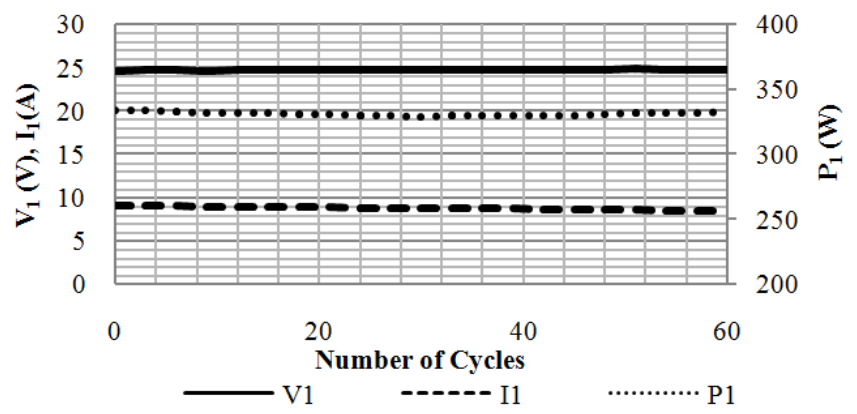

Fig. 11. The average rms voltage, average rms current and input power at low voltage virtual locked rotor test for the $3 \mathrm{hp}$ machine

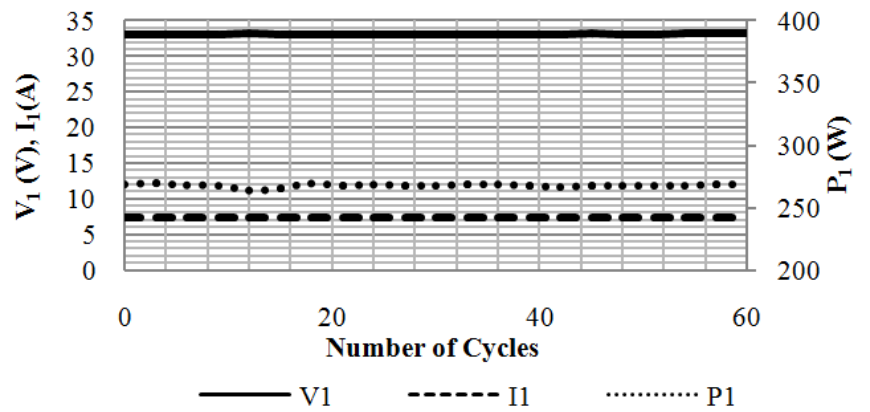

Fig. 12. The average rms voltage, average rms current and input power at low voltage virtual locked rotor test for the $7.5 \mathrm{hp}$ machine

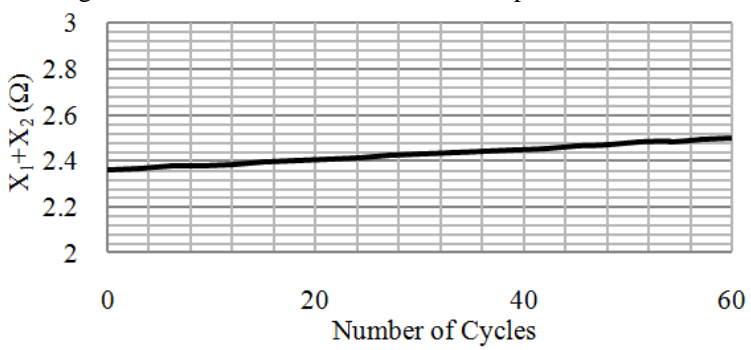

Fig. 13. The calculated sum of leakage reactances based on data from the low voltage virtual locked rotor test of the $3 \mathrm{hp}$ machine

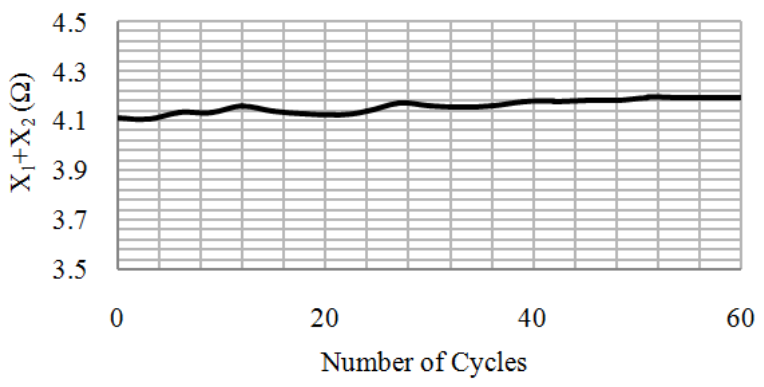

Fig. 14. The calculated sum of leakage reactances based on data from low voltage virtual locked rotor test of the $7.5 \mathrm{hp}$ machine

The new parameters are calculated based on the results of the proposed virtual locked rotor test and are shown in Table VII. As it can be seen, the parameters are significantly different from the ones found by the third impedance testing method of the IEEE standard 112 (shown in Table V).
TABLE VII

CORRECTED PARAMETERS OF THE 3 HP AND 7.5 HP MACHINES

\begin{tabular}{ccc}
\hline \hline Parameters & $3 \mathrm{hp}$ & $7.5 \mathrm{hp}$ \\
\hline $\mathrm{X}_{1}$ & $0.94 \Omega$ & $1.23 \Omega$ \\
$\mathrm{X}_{2}$ & $1.41 \Omega$ & $2.87 \Omega$ \\
$\mathrm{X}_{\mathrm{M}}$ & $19.36 \Omega$ & $68.10 \Omega$ \\
$\mathrm{R}_{\mathrm{C}}$ & $231.2 \Omega$ & $1534 \Omega$ \\
\hline
\end{tabular}

In the next section the corrected parameters are used to estimate the efficiency of the tested machines.

\section{EXPERIMENTAL VALIDATION OF THE MODIFIED EFFICIENCY ESTIMATION METHOD}

In this section the proposed efficiency estimation method is used to estimate the efficiency of $3 \mathrm{hp}$ and $7.5 \mathrm{hp}$ squirrel cage induction machines with the nameplate data as shown in the Table III and Table IV.

An experimental setup with the schematic as shown in Fig. 15 was used to measure the real efficiency of the tested machines.

In this set up a dynamometer was used to impose different torque levels on the shaft of the tested induction motor. A torque/speed sensor has been used to measure the accurate speed and torque values at each loading point. The measured values of efficiencies are calculated based on these measurements and they are used as a reference in comparison to estimated efficiencies with the proposed method. Fig. 16 shows the overall view of the designed experimental setup in the laboratory.

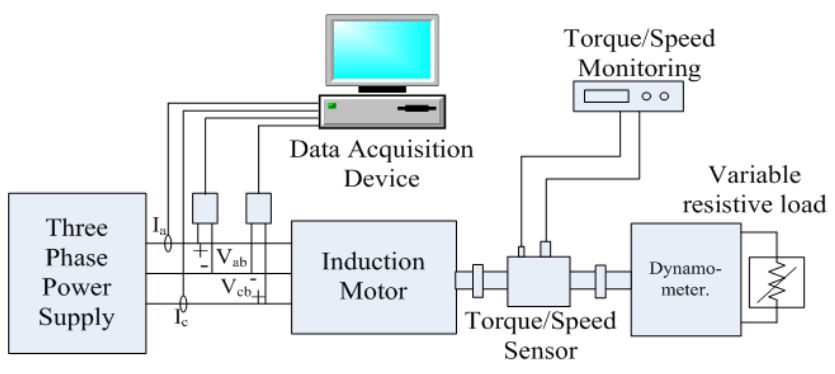

Fig. 15. Schematic of the test setup used for this experiment.

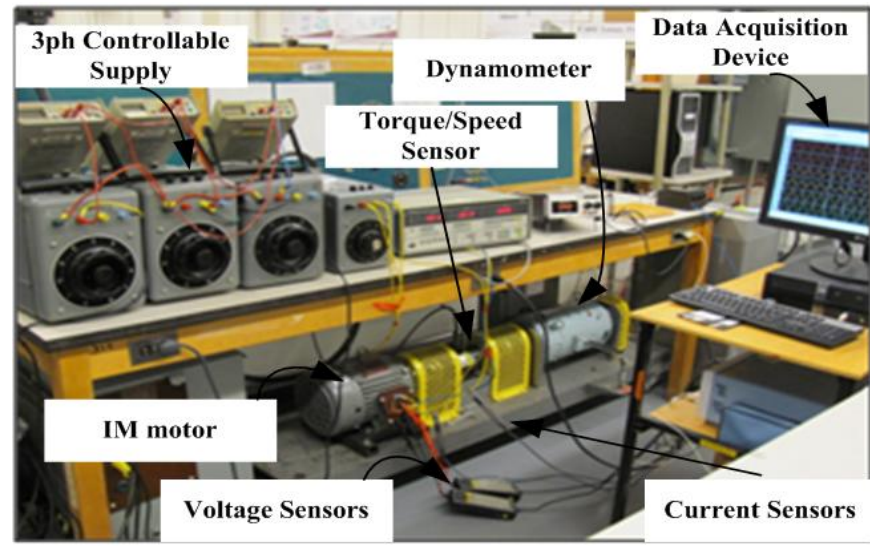

Fig. 16. The test setup of induction machine 
The measured efficiency values are compared with the estimated values from the no-load uncoupled testing and the results are shown in Tables VIII and IX for the $3 \mathrm{hp}$ and $7.5 \mathrm{hp}$ machines respectively. In the case of the $3 \mathrm{hp}$ motor, the machine was at the rated thermal steady state condition. In case of the $7.5 \mathrm{hp}$ motor the rated thermal condition was not achieved because the dynamometer was not capable of absorbing $7.5 \mathrm{hp}$ continuous power. To validate the proposed method, the machine was run at $0.75 \%$ of the rated load until the thermal steady state condition was obtained. Then the temperature of the machine at this operating point was used in the algorithm.

TABLE VIII

ESTIMATED EFFICIENCIES vS. MEASURED EFFICIENCIES FOR 3 HP MACHINE

\begin{tabular}{cccc}
\hline \hline \% of rated load & $\mathbf{5 0}$ & $\mathbf{7 5}$ & $\mathbf{1 0 0}$ \\
\hline Measured efficiencies & 77.27 & 80.15 & 80.48 \\
Estimated efficiencies & 76.29 & 79.14 & 79.4 \\
Error $(\%)$ & -0.98 & -1.01 & -1.08 \\
\hline
\end{tabular}

TABLE IX

ESTIMATED EFFICIENCIES VS. MEASURED EFFICIENCIES FOR 7.5 HP MACHINE

\begin{tabular}{cccc}
\hline \hline \% of rated load & $\mathbf{5 0}$ & $\mathbf{7 5}$ & $\mathbf{1 0 0}$ \\
\hline Measured efficiencies & 91.43 & 91.33 & 90.45 \\
Estimated efficiencies & 91.37 & 90.83 & 89.32 \\
Error $(\%)$ & -0.06 & -0.5 & -1.13 \\
\hline
\end{tabular}

\section{TESTING GENERALITY OF THE PROPOSED METHOD WITH FIVE DIFFERENT BIGGER INDUCTION MACHINES}

In order to verify the generality of the proposed method, five different bigger induction machines were tested in the LTEE laboratory of Hydro-Quebec which has a high quality test bench for motor efficiency measurement according to the IEEE Std 112 method B . In this facility, accuracies of $0.2 \%$ and a repeatability of $0.1 \%$ are attainable. The estimated efficiencies based on the proposed method are compared with the measured values based on the IEEE Std 112 method B and the results are shown in Table X to Table XIV for 15, 25, 50,100 and $150 \mathrm{hp}$ machines respectively.

TABLE X

ESTIMATED EFFICIENCIES VS. MEASURED EFFICIENCIES FOR 15 HP MACHINE

\begin{tabular}{cccc}
\hline \hline \% of rated load & $\mathbf{5 0}$ & $\mathbf{7 5}$ & $\mathbf{1 0 0}$ \\
\hline Measured efficiencies & 90.7 & 91.2 & 90.6 \\
Estimated efficiencies & 90.37 & 90.61 & 89.84 \\
Error $(\%)$ & -0.33 & -0.59 & -0.76 \\
\hline
\end{tabular}

TABLE XI

ESTIMATED EFFICIENCIES VS. MEASURED EFFICIENCIES FOR 25 HP MACHINE

\begin{tabular}{cccc}
\hline \hline \% of rated load & $\mathbf{5 0}$ & $\mathbf{7 5}$ & $\mathbf{1 0 0}$ \\
\hline Measured efficiencies & 92.8 & 92.8 & 92.0 \\
Estimated efficiencies & 92.57 & 92.93 & 92.45 \\
Error $(\%)$ & -0.23 & 0.13 & 0.45 \\
\hline
\end{tabular}

TABLE XII

ESTIMATED EFFICIENCIES VS. MEASURED EFFICIENCIES FOR 50 HP MACHINE

\begin{tabular}{cccc}
\hline \hline \% of rated load & $\mathbf{5 0}$ & $\mathbf{7 5}$ & $\mathbf{1 0 0}$ \\
\hline Measured efficiencies & 92.6 & 93.1 & 92.8 \\
Estimated efficiencies & 92.66 & 92.83 & 92.15 \\
Error (\%) & 0.1 & -0.3 & -0.6 \\
\hline
\end{tabular}

TABLE XIII

ESTIMATED EFFICIENCIES VS. MEASURED EFFICIENCIES FOR 100 HP MACHINE

\begin{tabular}{cccc}
\hline \hline \% of rated load & $\mathbf{5 0}$ & $\mathbf{7 5}$ & $\mathbf{1 0 0}$ \\
\hline Measured efficiencies & 94.9 & 95.5 & 95.5 \\
Estimated efficiencies & 94.54 & 94.73 & 94.3 \\
Error (\%) & -0.36 & -0.77 & -1.2 \\
\hline
\end{tabular}

TABLE XIV

ESTIMATED EFFICIENCIES VS. MEASURED EFFICIENCIES FOR 150 HP MACHINE

\begin{tabular}{cccc}
\hline \hline \% of rated load & $\mathbf{5 0}$ & $\mathbf{7 5}$ & $\mathbf{1 0 0}$ \\
\hline Measured efficiencies & 92.1 & 93.4 & 93.6 \\
Estimated efficiencies & 92.53 & 93.22 & 93.08 \\
Error $(\%)$ & 0.43 & -0.18 & -0.52 \\
\hline
\end{tabular}

\section{CONCLUSIONS}

In this paper, a simple method is proposed for full load efficiency estimation of induction machines from the uncoupled no-load testing that can be used in refurbishment facilities where the standard dynamometer testing is not affordable. The proposed method is a modified version of the equivalent circuit based method of the IEEE standard 112 which requires only the uncoupled no-load testing.

As verified by the experimental results, the proposed method is capable of estimating the efficiency of the machine within acceptable range of error.

\section{ACKNOWLEDGMENT}

The authors acknowledge the support of the Natural Sciences \& Engineering Research Council of Canada and Hydro-Québec for this work.

\section{REFERENCES}

[1] P. Pillay, K. A. Fendley, "The contribution of energy efficient motors to demand and energy savings in the petrochemical industry," IEEE Trans. Power Syst., vol.10, pp.1085-1093, May 1995.

[2] IEEE Standard Test Procedure for Polyphase Induction Motors and Generators, IEEE Standard 112, 2004.

[3] "Motor repair," Drivepower. [Online] Available: http://www.esource. com/public/pdf/Drivepower.pdf

[4] H. W. Penrose and B. Bauer, , "Time savings and energy efficiency through alternate electric motor rewind methods," in Proc. Elect. Electron. Insul. Conf., and Elect. Manuf. and Coil Winding Conf., 1995, pp. $457-460$.

[5] C. Wenping, K. J.Bradley, "Assessing the impacts of rewind and repeated rewinds on induction motors: is an opportunity for Re- 
designing the machine being wasted?," IEEE Trans. Ind. Appl. , vol.42, pp.958-964, July-Aug. 2006.

[6] E. d. C Bortoni, J. Haddad, A. H. M. Santos, E. M. d. Azevedo, R. A. Yamachita, "Analysis of Repairs on Three-Phase Squirrel-Cage Induction Motors Performance," IEEE Trans. Energy Convers. , vol.22, pp.383-388, June 2007.

[7] J.R. Holmquist, J.A. Rooks, M.E. Richter, "Practical approach for determining motor efficiency in the field using calculated and measured values," IEEE Trans. Ind. Appl., vol.40, pp. 242- 248, Feb. 2004

[8] J. S. Hsu, J. D. Kueck, M. Olszewski, D. A. Casada, P. J. Otaduy, L. M. Tolbert, "Comparison of induction motor field efficiency evaluation methods, " IEEE Tran. Ind. Appl., vol. 34, pp. 117-125, Feb. 1998.

[9] "In-plant electric motor loading and efficiency techniques," Ontario Hydro Rep., TSDD-90-043, 1990.

[10] J. S. Hsu, B. P. Scoggins, "Field test of motor efficiency and load changes through air-gap torque," IEEE Trans. Energy Convers., vol. 10, pp. 477-483, Sep. 1995.

[11] J. S. Hsu, P. L. Sorenson, "Field assessment of induction motor efficiency through air-gap torque," IEEE Trans. Energy Convers., vol. 11, pp. 489-494, Sep. 1996

[12] P. Pillay, V. Levin, P. Otaduy, J. Kueck, "In-situ induction motor efficiency determination using the genetic algorithm," IEEE Trans. Energy Convers., vol. 13, pp. 326-333, Dec 1998.

[13] T. Phumiphak, C. Chat-uthai, "An economical method for induction motor field efficiency estimation for use in on-field energy audit and management," in Proc. IEEE Int. Conf. Power System Technology, 2004, pp. 1250- 1254.

[14] M. S. Aspalli, S. B. Shetagar, S. F. Kodad, "Estimation of induction motor field efficiency for energy audit and management using genetic algorithm," in Proc. IEEE Int. Conf. Sensing Technology, 2008, pp. 440445.

[15] M. Cunkas, T. Sag, "Efficiency determination of induction motors using multi-objective evolutionary algorithms", Elsevier J. Advances in Engineering Software, vol. 41, pp. 255-261, Feb. 2010

[16] Bin Lu, Cao Wenping; I. French, K. J. Bradley, T. G. Habetler, "Nonintrusive efficiency determination of in-situ induction motors using genetic algorithm and air-gap torque methods," in Conf. Rec. IEEE 42nd IAS Annual Meeting, 2007, pp. 1186-1192.

[17] V.P. Sakthivel, R. Bhuvaneswari, S. Subramanian, "Non-intrusive efficiency estimation method for energy auditing and management of inservice induction motor using bacterial foraging algorithm" IET Electr. Power Appl., vol. 4, no. 8, pp. 579-590, March 2010

[18] F. Waldhart, J.P. Bache, "Online efficiency determination of three phase asynchronous machines by start-up data," in Proc. IEEE Int. Conf. Diagnostics for Electric Machines, Power Electronics and Drives, 2009, pp.1-6.

[19] C. Grantham, H. Tabatanaei-Yazdi, M.F. Rahman, "A novel method for rapid efficiency measurement of three phase induction motors," IEEE Trans. Energy Convers., vol.14, pp.1236-1240, Dec 1999

[20] D.J. McKinnon, C. Grantham, "Improved efficiency test methods for three-phase induction machines," in Conf. Rec. IEEE 40th IAS Annual Meeting, 2005 , pp. 466- 473.

[21] J.D. Kueck, M. Olszewski, D. A. Casada, J. Hsu, P. J. Otaduy, and L. M Tolbert, "Assessment of methods for estimating motor efficiency, and load under field conditions," Oak Ridge National Laboratory Rep., ORNL/ TM-13165, 1996.

[22] Y. El-Ibiary, "An accurate low-cost method for determining electric motors' efficiency for the purpose of plant energy management," IEEE Tran. Ind. Appl., vol.39, pp. 1205- 1210, Aug. 2003.

[23] B. W.Williams, J. K. Goodfellow, T. C. Green, "Sensorless speed measurement of inverter driven squirrel cage induction motors," in Proc. IEEE Int. Conf. Power Electronics and Variable-Speed Drives, 1991, pp. 297-300.

[24] A. G. Siraki, P. Pillay, "An algorithm for non-intrusive in-situ efficiency estimation of induction machines operating with unbalanced supply conditions", Accepted for publication IEEE Trans. Ind. Appl., 2012

[25] IEC 60034-2-1, Rotating Electrical Machines-part2-1, 2007, Standard method for determining efficiency and losses from tests (excluding machines for traction vehicles.)

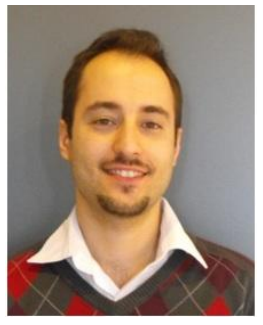

Arbi Gharakhani Siraki (S'07) received the B.S. degree in electrical engineering from Azad University, Tehran, Iran, in 2004 and the M.Sc. degree in electrical engineering from K.N.T University of Technology, Tehran, Iran, in 2007.

$\mathrm{He}$ is currently working toward the Ph.D. degree, in the Power Electronics and Energy Research Group, Department of Electrical and Computer Engineering of Concordia University, Montreal, Canada.

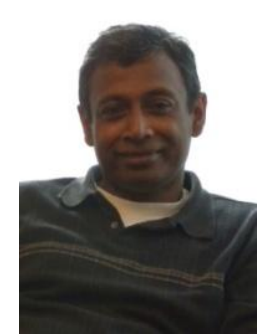

Pragasen Pillay (F'05) received the Bachelor's degree from the University of Kwa-Zulu Natal, Durban, South Africa, in 1981, the Master's degree from the University of Kwa-Zulu, Natal, Durban, South Africa, in 1983, and the Ph.D. degree from Virginia Polytechnic Institute and State University, Blacksburg, in 1987.

Currently, he is a Professor in the Department of Electrical and Computer Engineering, Concordia University, Montreal, Canada, where he holds the NSERC/Hydro Quebec Industrial Research Chair.

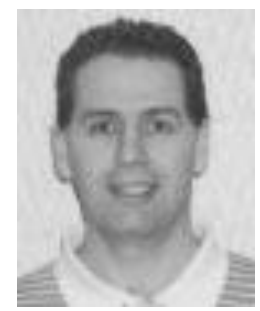

Pierre Angers received the B.S. degree in electrical engineering from the Université du Québec à TroisRivières, Trois-Rivières, QC, Canada, in 1986. Since 1988, he has been a Research Engineer with LTEE-Hydro-Quebec, Shawnigan, QC, Canada. His areas of interest are motors, power quality, power electronics, measurement, data acquisition, and electrotechnologies. He has been involved in the design, installation, and startup of the motor

and adjustable-speed drives test facility located at the LTEE. He is currently responsible for operation of the test facility accredited ISO Guide 17025 by the Standards Council of Canada and by the Canadian Standards Association (CSA). He has also participated in many studies related to losses in motors and power quality issues with adjustablespeed drives. He is a member of the technical subcommittee of CSA Standard C390-98, "Energy Efficiency Test Methods for Three-Phase Induction Motors."

Mr. Angers is a member of the "l’Ordre des Ingénieurs du Quebec." 